\title{
A criação intertextual nos processos mediáticos
}

$\frac{\text { AnNA MARIA BALOGH }}{\text { Escola de Comunicações e Artes/USP }}$ 


\section{Resumo}

A sociedade contemporânea, através de avanço tecnológicos, facilitou o acesso dos usuários a um número cada vez maior de textos. Por esta razão, entre outras, a atividade artística tende, hoje, a pautar-se por estratégias de enunciação centradas na colagem, na citação, na reelaboração e na metamorfose de textos prévios em vez de se guiar pelos conceitos de obra única e original da arte pretérita. Esta intertextualidade transformadora, eixo de grande parte da criação contemporânea é cada vez mais exacerbada na mídia, cinema, e sobretudo TV, como se analisa neste artigo.

\section{Palavras-chave}

estratégias de enunciação, intertextualidade, mídia

\section{Abstract}

New technologies make the access to numerous texts easier for any user in contemporary society than it used to be in the past. In such context, art and communication works tend towards enounciation strategies axed in various forms of collage, use of quotations, remakes or metamorphosis of previous texts, rather than rely on concepts of originality and uniqueness essential in traditional art. Creation is nowadays based on intertextual relations, on quite bold forms of experiment on this field in films and TV series as shown in the article.

\section{Key words}

enounciation strategies, intertextuality, media 


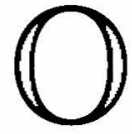

s meios de comunicação de massas invadiram o quotidiano do homem contemporâneo gerando uma autêntica pululação de textos verbais, visuais, audiovisuais e multimediáticos na nossa cultura. Um dos resultados mais palpáveis deste universo plural e fragmentário é um fazer artístico que não consiste mais exclusivamente na elaboração de obras originais, como ocorria no pretérito, mas sim na citação, na reelaboração, na metamorfose de obras já existentes.

O reprocessamento constante da textualidade prévia, característico de boa parte da produção artística atual, é facilitado por avanços tecnológicos disponíveis sobretudo no âmbito da tecnologia eletrônica. Da TV (com VHS) ao computador e à multimídia, os equipamentos vão-se tornando cada vez mais acopláveis, acessíveis e manipuláveis para um número crescente de pessoas.

$O$ pesquisador atento não pode permanecer alheio a este rico universo intertextual em constante mutação. Trata-se de uma intertextualidade transformadora muito ampla: abarca imagens estáticas, como a instigante série de experimentações feitas por Pablo Picasso a partir de As Meninas, de Velásquez, assim como imagens dinâmicas, sobretudo as presentes nas assim chamadas "semióticas sincréticas" (Floch, 1983, pp. 3-4).

As semióticas sincréticas, sobretudo o cinema, a TV, o vídeo e a publicidade são construídas através do entretecer de várias materialidades e de linguagens diversas. É neste âmbito que tentaremos esboçar um primeiro elenco de relações intertextuais transformadoras e entrever a sua complexidade. 
Os conceitos de intertextualidade que temos em mente são os de Julia Kristeva: "L'intertextualité désigne non pas une addition confuse et mystérieuse d'influences, mais le travail de transformation et d'assimilation de plusieurs textes opéré par un texte centreur qui garde le leadership du sens." (1976, pp. 27; 262) e de Michel Arrivé: "Texte absorbant une multiplicité de textes tout en restant centré par un sens." (1976, pp. 27; 267)'

\section{O literário e o sincrético}

A intertextualidade transformadora na passagem do verbal (literatura) ao sincrético (cinema, TV). Trata-se de um tipo de transmutação ${ }^{2}$ já consagrado. Há, em menor escala, o processo inverso, ou seja, do sincrético ao literário.

No primeiro tipo de transposição o leque de exemplos é muito vasto: vai desde os clássicos, como $O$ Vento Levou dirigido por Victor Fleming (EUA, 1939), adaptado do romance homônimo de Margaret Mitchell, até cult-movies como Blade Runner, de Ridley Scott (EUA, 1982), transposto do pequeno romance de ficção científica de Phillip K. Dick, Why do androids dream with electric sheaps?

Em obra dedicada ao estudo de filmes e minisséries brasileiras adaptadas (Balogh, 1996) pudemos constatar que a grande maioria dos exemplos analisados mantinha fielmente o nível narrativo na passagem do texto de partida para o texto de chegada. As únicas diferenças mínimas se verificavam na mudança da ordem seqüencial das funções ( $V l$ das Secas, Nelson Pereira dos Santos), no retardamento de uma função para manter o "suspense" (a revelação do anão sobre a fuga de Inocência, no filme homônimo de Walter Lima Júnior) entre outros.

As grandes mudanças de ordem criativa na transmutação do literário para o sincrético (cinema e TV) ocorrem sobretudo no nível discursivo com ênfase maior nas categorias da atorialização, da espacialização, da temporalização e da figurativização.

1. apud Jenny, 1976.

2. Muito embora o termo consagrado seja adaptação, os termos "tradução intersemiótica" e transmutação nos parecem os mais adequados sobretudo se pensarmos na passagem da palavra para som e imagem. (Jakobson, s/d.) 
Em Grande Sertão: Veredas (Globo) há uma cronologização da temporalidade, totalmente assincrônica no romance. Há também uma des-sincretização do Narrador e do Sujeito Operador, sincretizados em Riobaldo no romance, perdendo-se o caráter nostálgico de memória pessoal presente no literário.

Em Chapadão do Bugre (Bandeirantes) ocorre o inverso, o romance de Mário Palmério é bastante tradicional no tocante à temporalização e a minissérie transmuta a temporalidade de forma totalmente assincrônica, usando negativização das imagens, preto e branco, tanto para os flash-backs, quanto para os flash-forwards na ação.

Em Vidas Secas há uma magnífica retomada das limitações dos atores do Sujeito do Desejo, sobretudo de Fabiano e do menino mais velho, cuja falta de competência para atingir o objeto desejado se manifesta na figura do semi-círculo formado mormente por sua situação e sua movimentação no espaço.

Em Macunaíma de Joaquim Pedro de Andrade há uma belíssima recriação intertextual do caráter plural da suite musical que orientou a elaboração do romance de Mário de Andrade, na análise de Gilda de Mello e Souza. Esta pluralidade é retomada por Joaquim Pedro ao reciclar a música (desde Roberto Carlos até Villa-Lobos), o próprio cinema (trazendo atores e situações da chanchada, com Grande Otelo e Wilza Carla), o teatro, na elaboração dos cenários, as referências políticas, a retomada do olhar antropofágico oswaldiano na transposição fílmica.

Nota-se que, tanto na televisão que freqüentemente contou com altos orçamentos na produção das minisséries, quanto no cinema, cujos recursos eram em geral mais parcos, a variedade nos processos criativos intertextuais se manifesta de forma contundente no nível discursivo.

\section{Do sincrético ao literário}

Devido à ampla penetração da TV junto à população brasileira em geral, começam a se multiplicar obras transpostas do televisual ao literário. Antes este tipo de transposição se resumia às publicações dos roteiros de filmes consagrados em livro. Neste caso, as obras publicadas têm muito mais valor de um registro escrito da volátil memória televisual do que uma atividade artística 
transformadora em termos estéticos como ocorre com a transposição no sentido inverso. ${ }^{3}$

\section{Do sincrético ao sincrético}

As diversas formas de intertextualidade transformadora na passagem de uma semiótica sincrética a outra semiótica sincrética.

\section{O cinema no cinema}

A citação, o reaproveitamento do cinema pelo próprio cinema são recursos freqüentemente utilizados. Neste âmbito, o número de exemplo possíveis é praticamente inesgotável. O trabalho sobre os textos prévios pode-se dar em gradações muito diversas. Existem algumas formas de citação bastante óbvias e superficiais como a que ocorre em Os Intocáveis, de Brian de Palma (EUA, 1987). No embate derradeiro entre os intocáveis e os gangsters sobreviventes de lutas anteriores na imponente Union Station, de Chicago, temos uma citação a uma das cenas mais dramáticas do episódio "A Escadaria de Odessa" do filme $O$ Encouraçado de Potemkine, de Serguei Eisenstein. Tal como no filme citado, um carrinho, com um nenê dentro, desce escadaria abaixo, desgovernado, ante os olhos atônitos da mãe, impotente para agir, e dos demais. No filme de Brian de Palma a dramaticidade da cena tem um leve toque de ironia, e oferece um contraponto à luta sangrenta entre policiais e gangsters, que ocorre simultaneamente à descida do carrinho desgovernado.

3. Anos Rebeldes, minissérie da Globo, de autoria de Gilberto Braga, foi romanceada por Flávio de Campos para a Editora Globo (São Paulo: 1992). Novelas famosas da mesma emissora foram traduzidas para a literatura em séries populares tais como As Grandes Telenovelas da Rio Gráfica, que conta com títulos como Irmãos Coragem (1985), novela da célebre Janette Clair. Outra série Campeões de Audiência - da Editora Globo, traz títulos como Roque Santeiro, de Dias Gomes, romanceada por Eduardo Borsato (1987) e Roda de Fogo, de Lauro César Muniz e Marcilio Moraes, transposta à literatura por Helena Muniz de Carvalho (1987). 
Há formas de retrabalhamento intertextual bem mais sutis, como a que ocorre com Bom dia Babilônia (Itália, 1986), filme que faz referência constante a Intolerância de Griffith de uma forma mais oblíqua. Acaba sendo uma mescla de making of a posteriori com uma espécie de biografia romanceada. Enfoca a estória de dois irmãos italianos, arquitetos imigrantes, que colaboram na realização dos cenários durante as filmagens de Intolerância do pioneiro cineasta americano ( um ator encarnando o próprio Griffith participa de algumas cenas). $\mathrm{O}$ resultado é uma belíssima estória ficcional de amor e ódio entre seres humanos e outra, metalingüística, de amor ilimitado pelo cinema tal como era feito em seus primórdios.

Blade Runner-O Caçador de andróides, parece ser um dos mais contundentes exemplos de uma intertextualidade transformadora em que o cinema retrabalha todo um conjunto de textos, escolas, estilos e gêneros fílmicos que vão desde o "noir" revisto e acelerado em termos de edição com influência da publicidade, até a ficção científica, a atual e a pioneira, como o filme Metrópolis, de Fritz Lang (1926). Falaremos deste filme de forma detalhada mais adiante.

\section{A viagem por diferentes veículos}

As transposições de uma mesma estória, ou de um personagem, para os mais diversos veículos adquirindo matizes diversos em cada transposição de acordo com as servidões impostas pela media para a qual o produto audiovisual é adaptado. Um caso bem típico é o de Batman. A estória se popularizou primeiro na mídia impressa na Revista Detective Comics (EUA, 1939). Depois alcançou bastante sucesso numa versão serializada para a TV americana (1966-1968, $\mathrm{ABC}$, EUA, diário às $19 \mathrm{~h} 30 \mathrm{~min}$ ). Posteriormente foi transposto para o cinema (Tim Burton, EUA, 1992), mas já agora sem o Robin, considerado dispensável pelo público em pesquisa de audiência, na primeira versão fílmica. Já Batman, o retorno, aposta na possibilidade de sucesso da sensual "mulher-gato", vivida por Michelle Pfeiffer que, de fato, rouba todas as cenas. Outro sinal dos tempos: os vilões são um grande sucesso. As cores e efeitos visuais, um tanto 
"psicodélicos" da série televisual recebem nos filmes um tratamento bem mais gótico, atual e esmerado, mas a base narrativa e o universo de valores maniqueísta permanecem.

\section{A ruptura de tipologias discursivas}

Em algumas das transmutações feitas de uma semiótica sincrética para outra, ocorrem rupturas em tipologias discursivas já consagradas. Em sua obra Viagem à Irrealidade Quotidiana, Humberto Eco diferencia os discursos informativos dos discursos fictícios ao falar da televisão. Aponta várias diferenças entre ambos, sendo as mais notáveis o compromisso com a verdade no primeiro e com a verossimilhança no segundo. Além disso, ao veicular a informação, o locutor olha firmemente para o espectador, quando na ficção, via de regra, os atores só dirigem seu olhar para os copartícipantes do universo fictício, que não inclui o espectador. $\mathrm{O}$ tempo e o espaço da ficção podem ser extremamente variáveis, enquanto que o espaço e o tempo da informação só podem ser aqueles dos fatos. A um determinado ponto do artigo, no entanto, Eco constata a tendência (1984, p. 191) de um entrelaçamento cada vez maior entre a informação e a ficção.

Esses limites entre os dois discursos foram cada vez mais subvertidos em textos fílmicos e televisivos contemporâneos. $\mathrm{Na}$ novela Roda de Fogo, da rede Globo, o corrupto advogado Mário Liberato (Cecil Thiré) encontra a morte de forma intencionalmente similar à de Lee Oswald, assassino do presidente Kennedy, morto a tiros diante das câmeras da TV americana. A ficção incorpora e reinterpreta a realidade documentada e parece encerrar a cena com uma forte moral implícita: todos os crápulas merecem uma morte similar.

No filme $J F K$ (EUA, Oliver Stone), o diretor reinterpreta também o documental ao incorporar num magnífico trabalho de montagem, o filme da morte do Presidente Kennedy feito pelo cineasta amador Abrão Zapruder- veiculado à exaustão por todos os noticiários da época- para comprovar sua tese de que o estadista assassinado teria sido vítima de uma grande conspiração. Em ambos os exem- 
plos, os realizadores incorporam o documentário à ficção e subvertem os limites existentes entre essas tipologias discursivas para recriar o sentido através da transformação intertextual.

\section{A voracidade televisual}

A citação, a transposição de textos literários, musicais, fílmicos e quadrinhos na TV é freqüente. Talvez o exemplo mais contundente deste tipo de mutação intertextual seja a série Armação Ilimitada: parodiava os vídeo clipes, o jornalismo, citava obras de Glauber Rocha, utilizava onomatopéias e elementos visuais dos quadrinhos. Curiosamente Armação Ilimitada fazia parte de uma estratégia de uma criação de "Novos Formatos" na Globo e trazia, nos anos 80, alguns procedimentos intertextuais (sobretudo a remissão aos quadrinhos) que caracterizaram o cinema de "Nouvelle Vague" francesa, nos anos 60, sobretudo a cinematografia de Jean Luc Godard. Os espectadores veteranos captaram a similaridade entre ambas as estratégias de enunciação, os jovens adoraram as 'novas armações'.

Mais recente na diacronia, a novela das sete de Carlos Lombardi, Uga, Uga, também fez um instigante diálogo com os quadrinhos: sempre que a imagem televisiva de uma cena da novela congelava, antes dos intervalos, ela se transformava numa imagem de estória de quadrinhos.

As técnicas de computação gráfica vão sendo cada vcz mais incorporadas ao quotidiano do fazer televisual, é, no entanto, nas vinhetas de abertura que elas ocupam um espaço privilegiado. Neste campo já podemos pinçar alguns exemplos de intertextualidade transformadora controversa como o da novela Tieta (Globo, 1989, pp. 20;30). Causou polêmica o aproveitamento que o vídeo-maker Hans Donner fez nesta abertura das técnicas de Zhig Rybyncki, em seu vídeo experimental The Fourth Dimension (1986), no qual se obtém o efeito do corpo humano se enroscando em torno de um eixo, qual uma serpente, imitado bem de perto na abertura da novela brasileira. Em alguns casos parece difícil estabelecer o limite entre a recriação e o simples plágio. 


\section{A criação intertextual: o apogeu de um processo na TV}

No processo de radicalização cada vez maior das transformações na criação intertextual, as simples citações de trechos de obras, como vimos em $O$ s Intocáveis, vão cedendo lugar a processos mais complexos em termos de subversões e mesclas, como Bom dia, Babilônia e $J F K$. Dentro desta tendência geral de acirramento das experimentações intertextuais no sentido de quebrar casa vez mais os limites das diferentes tipologias discursivas, bem como no sentido de abarcar textualidades cada vez mais abrangentes (respondendo por gênero, estilos, escolas e etc.) gostaríamos de analisar, ainda que brevemente, dois exemplos emblemáticos, e, portanto, amplamente ilustrativos deste tema que nos ocupa: na televisão, a novela das sete, da Globo, na TV e no cinema, Blade Runner, o caçador de andróides.

A novela das sete é a que tem feito as experimentações mais subversivas com gêneros literários, teatrais e fílmicos, bem como com clipes musicais, entre outros. Isto vem ocorrendo desde Guerra dos Sexos, Sassaricando e outros que analisaremos um pouco mas detidamente a seguir.

Que rei sou seu? (Globo) centrou a trama num grupo de espadachins liderados por Jean Pierre (Edson Celulari) cujas tramas narrativas nos remetem aos velhos mosqueteiros de Alexandre Dumas na literatura, bem como à outros romances como Scaramouche ou Capitão Blood de Rafael Sabatini. O cinema retomou bem esse gênero de capa e espada, sobretudo nos heróis vividos por atores como Stewart Granger e Errol Elynn. O visual de Jean Pierre na novela, bigodinhos finos, cabelo pajem ou rabo de cavalo, relembram os personagens vividos por aqueles atores no cinema. A novela, no entanto, como é praxe em sua estrutura, mescla a ficção intertextual e a realidade e a corrupção dos conselheiros da rainha remete a muitas situações da realidade política brasileira.

A obra trouxe também algumas deliciosas blagues televisivas de ordem intertextual para refrescar a memória dos espectadores 
veteranos. Numa cena, Bidet (John Hebert) conselheiro da rainha Valentina (Teresa Raquel), depara com uma bela dama (Eva Wilma) recém chegada ao palácio e a saúda: "Alô, doçura!" Trata-se, como é sabido, do título de uma das séries românticas mais populares da antiga TV Tupi, protagonizada justamente por esses dois atores que eram na época casados inclusive na vida real.

A novela Vamp (Globo, 1991) também se estruturou com base na mescla de gêneros prévios, vampiro ou horror, existentes tanto na literatura (Bram Stocker), quanto no cinema (Nosferatu, do expressionismo alemão, por exemplo). Tanto em termos das funções narrativas quanto em termos dos elementos técnico-expressivos, foram respeitadas as convenções do gênero. Até mesmo o nome dado ao líder dos vampiros, o conde Vladimir Polansky (Ney Latorraca) é uma homenagem a um dos cineastas mais destacados do gênero.

A aproximação ao clipe musical de horror, como Thriller de Michael Jackson, inspirou a abertura da novela e de alguns dos ambientes visuais nela criados. O retrabalhamento intertextual mais evidente, no entanto, se fez com outro clipe do mesmo mega-star: Black or White. Na morte de alguns dos representantes do mal, os vampiros, se utilizou a mesma metamorfose seqüenciada de rostos, obtida por computador, que causou tanto frisson na apresentação do clip de Michael Jackson.

Como, no entanto, na televisão a criação parece ser presidida pela lei de Lavoisier, o mundo dos vampiros e dos clips dark se mesclou com uma pitada de comédia romântica de Hollywood: $\mathrm{O}$ capitão Jonas, vivido por Reginaldo Farias, apaixonou-se por uma intelectual pesquisadora da história dos vampiros, vivida por Joana Fomm, que corresponde à sua paixão e o resultado é que cada um levará os respectivos seis filhos para viverem numa pousada num quotidiano cheio de peripécias hilárias.

A televisão se caracteriza pela sua extraordinária capacidade de absorção de outras linguagens, gêneros e textos, bem como por sua enorme voracidade ao fazê-lo, posto que permanece praticamente o dia todo e todos os dias do ano no ar. Por este motivo, alguns formatos televisivos, como o que analisávamos, ilustram de 
forma contundente a intertextualidade mutante que enfocamos neste artigo.

\section{A recriação intertextual transformadora no cinema}

O processo, no entanto, não é exclusivo da TV, é apenas levado ao paroxismo neste veículo, ele existe também no cinema. Muitos filmes recentes recorreram das formas mais diversas à recriação intertextual. Houve uma verdadeira febre de retrabalhamentos do noir que apareceu, reinventado, a cores, em Hammet e Chinatown bem como em preto e branco, com instigantes exercícios de montagem, em Cliente morto não paga, entre vários outros.

O exemplo mais cabal, no entanto, nos parece ser, sem dúvida alguma, Blade Runner de Ridley Scott. Nesta obra, o exercício de recriação intertextual foi feito com muito esmero narrativo e visual e muita coerência em termos de conhecimento da diacronia dos estilos e dos gêneros fílmicos retrabalhados. Neste cult-movie, o diretor remete também ao noir, dos anos 40 e 50 de Hollywood, assim como à ficção científica.

Em meio às maquetes de Corporação Tyrell magnificadas pelas tomadas de câmera, às naves se deslocando no espaço aéreo, próprias das ficções científicas, em meio às quinquilharias eletrônicas e à urbe super-populosa, próprias da Los Angeles futurista de 2.019, espaço representado do filme, encontramos objetos, vestuários, interiores, atitudes de personagens inteiramente calcadas nos filmes noir. Até mesmo as funções narrativas executadas por Deckard são próprias dos detetives do noir: investigação, perseguição dos transgressores (andróides), punição dos transgressores (com exceção de Rachel).

Deckard (Harrison Ford), o blade runner, vestindo uma gabardina meio surrada, com jeito desleixado e durão, nada mais é do que um Phillip Marlowe que aterrizou numa ficção científica. Rachel (Sean Young), a replicante, é longilínea, usa roupas justas com brilhos estratégicos ou com peles, tem cabelos presos, é misteriosa, super atraente e ambígua, no mais puro estilo das femmes fatales do 
noir. A relação entre ambos retoma a explosiva mescla de atração e repulsão próprios daquele gênero (quem não lembra dos personagens vividos por Lauren Bacall e Humphrey Bogart?) determinando muitas das modulações passionais e rítmicas do filme.

A sequiência em que o chefe de polícia, Briant, praticamente intima Deckard a ser um blade runner, retoma a relação de rispidez competitiva, e colaboração forçada existente entre policiais e detetives nos policiais da década de 40 . O próprio escritório de Briant, com a velha escrivaninha, a luz filtrada pela persiana, a indefectível garrafa de bebida, o abat-jour, bem que poderia ser o de Sam Spade.

Blade Runner retrabalha no filme a cores o alto contraste de luz dos policiais antigos, estes em preto e branco. Em muitas cenas vemos a luz esculpindo literalmente os rostos de Rachel e Deckard. $\mathrm{O}$ de Deckard sobretudo na cena em que visualiza os replicantes na tela do computador com Briant e o de Rachel durante o interrogatório a que a submete Deckard na corporação Tyrell.

Os enquadramentos se fecham nas tomadas de interiores (o apartamento de Leon) como nos noir tradicionais, mas a montagem se acelera bastante provavelmente como resultado da experiência do cineasta na publicidade.

Voltando mais longe na diacronia, descobrimos nas tomadas aéreas iniciais do filme um edifício antigo que nos remete a Metrópolis, de Fritz Lang, filme que Blade Runner retrabalha em muitos aspectos. A própria Rachel, andróide que parece humana, remete ao personagem similar Maria, do filme de Lang, operária que se transforma em robô. Em ambos os filmes, os poderosos vivem no alto e a plebe numerosa nas partes baixas da cidade. Esta dicotomia foi depois revisada pelo noir: upperworld, a sociedade legal; underworld, o mundo dos criminosos.

Muitos dos diretores dos policiais antigos dos Estados Unidos se formaram na cultura européia. Alguns chegaram à América fugindo do nazismo. De forma coerente, há no filme várias menções àquela cultura, das quais destacamos uma. A replicante Priss, no seu encontro com J.F. Sebastian em meio à metrópole suja, aparece contra a luz, loura, de preto, com cinta liga, qual uma versão pop do "anjo azul" fascinando o indefeso rapaz. 
Nem mesmo as menções literárias escapam ao intrincado tecido de relações do filme. Um dos edifícios visitados por Deckard na sua perseguição aos andróides tem escrito na entrada do portal "Bradbury" numa remissão a Ray Bradbury, consagrado autor de romances de ficção científica.

Poderíamos seguir citando indefinidamente tal a riqueza e a coerência do filme na utilização da intertextualidade transformadora que estivemos analisando. Blade Runner traz a passagem do romance de Phillip K. Dick para o cinema (do literário ao sincrético), a reutilização de dois gêneros fílmicos amalgamados (noir e "ficção científica"), a citação de outros tantos filmes mencionados. Como se não bastasse, há uma nova versão do filme que leva este processo ao paroxismo. Na nova versão, o diretor corta a voz off de Deckard, cuja utilização desagradou tanto o cineasta quanto o ator Harrison Ford na versão anterior e que, no entanto, estava em perfeita consonância com a estética do noir, importante fonte de criação do filme, onde tal recurso era freqüente.

\section{O papel dos gêneros}

Cabe lembrar ainda que a criação sedimentada nesta intertextualidade transformadora exige uma competência ampla e plural dos realizadores, por vezes o domínio de várias séries culturais, e competência similar dos receptores na outra ponta do processo.

Os gêneros constituem elementos normativos muito importantes na cultura popular, principalmente na TV, orientando a descodificação dos espectadores, dado nada desprezível num universo caracterizado pela velocidade, pela voracidade de consumo dos programas e sua consequiente obsolescência programada.

A recriação intertextual é característica marcante na TV contemporânea, como aponta Mauro Wolf:

Los géneros televisivos de actualidad tienen un rasgo común: su carácter mixto, compuesto. Tanto los programas con estructura mosaical como aquellos de estructura monográfica se configuran como ensamblaje de partes, de fórmulas, géneros, y subgéneros. (Anàlisi, 1984, pp.194-195) 
Os gêneros se revelam também dados importantes na apreensão das transformações, das metamorfoses, das apropriações que manifesta esta textualidade pós-moderna típica de um veio criativo dos processos mediáticos. Neste sentido a visão de Fiske sobre o tema na TV nos parece a mais adequada para a sua compreensão:

Um gênero visto como um texto, deveria ser definido como um conjunto mutante de características que são modificadas a cada novo exemplo que é produzido. Cada programa vai ser constituído pelas características principais de seu gênero, mas tem a propriedade de incluir algumas outras. Considerar um programa como pertencente a um gênero ou outro pressupõe decidir qual o conjunto de categorias mais importantes. (Television Culture, 1987, p. 11)

\section{Reflexões finais}

A televisão, devido à sua presença diária no quotidiano dos espectadores, bem como à voracidade de consumo dos programas, assim como à longa extensão de alguns dos formatos fictícios, como a novela, tende a um aproveitamento hiperbólico das textualidades. Vimos, ao analisar brevemente as novelas das sete, que além das habituais citações esparsas e pontuais, a TV tende tomar como referência conjuntos de textos cada vez mais amplos: gêneros inteiros, por vezes dois ou mais gêneros entre mesclados dentro da trama narrativa. Em alguns casos, os gêneros citados e recriados abarcam tanto os primórdios literários, quanto as realizações fílmicas, e em alguns casos até as criações musicais e televisivas já existentes.

O cinema, bem mais compacto em termos de extensão e menos voraz em termos de elaboração e consumo tende a aprofundar e radicalizar as rupturas e subversões desta recriação intertextual rompendo os limites das diferentes tipologias discursivas (making of $\mathrm{x}$ ficção; informação $\mathrm{x}$ ficção) das estratégias discursivas (vídeo amador $\mathrm{x}$ TV e cinema profissional), entre outras.

No caso de Blade Runner há uma recriação primorosa dos elementos discursivos, sobretudo da temporalidade. O filme volta 
cerca de quatro décadas e retoma assim a estética do noir e salta mais ou menos o mesmo tempo na representação da Los Angeles "futurista" e retrabalha a "ficção científica". Na retomada do noir mantêm-se os enquadramentos fechados e claustrofóbicos do gênero (visita ao apartamento de Leon), mas as sequiências se agilizam em relação ao "noir" tradicional, influência provável da lide de Ridley Scott com a publicidade, o alto contraste de luz, característico do noir e retrabalhado nas cores com filtros.

A ficção científica recupera cults do gênero, como Metrópolis não apenas nas cenas citadas, mas em todo caráter ambíguo e único de Rachel tal como o de Maria no filme de Lang, até mesmo na cena da primeira entrada de Rachel em que há um escurecimento das grandes janelas, similar ao que ocorre no escritório do dono da empresa em Metróplis. O resgate do passado fílmico vai ainda mais longe recuperando o cinema alemão, não apenas no "anjo azul pop", Priss, mas no gosto pela expressionista teatralidade e pelos símbolos, principalmente na casa de J. F. Sebastian e de Tyrell.

Acreditamos que os exemplos citados e os analisados tenham constituído uma boa amostragem desse rico processo de criação de uma intertextualidade cada vez mais radical e mais transformadora. Novas formas surgem a cada dia. Cabe ao leitor permanecer atento e fazer o seu próprio "tecido de relações".

\section{Bibliografia}

BAKONYI, Ivan. s/d. Contribution à une reflexion sur quelques formes d'emprunts iconíques au cinéma. In: Les Cahiers du Circav. Hommage à Christian Metz, Gerico-Université de Lille, 3, n 6/ 7: $29-46$

BALOGH, Anna Maria. 1985. Análise do nível superficial da narrativa do filme "Blade Runner: o caçador de andróides", de Ridley Scott. Significação-Revista Brasileira de Semiótica, Araraquara: UNESP-(5): 53-58, julho.

1996. Conjunções, Disjunções, Transmutações. Da Literatura ao Cinema e à TV. São Paulo: Annablume, ECA/USP. 
. 1998. "La tèlèvision brèsilienne at-elle une vie intelligente?" Rev. Champs Visuels- Revue Interdisciplinaire de Recherches sur l'image, La tèlèvision au miroir (2). ParisMontréal: Editions L'Harmattan, nº 9, 80-92, mars.

1996. Noir: o corpo como cifra do erótico emergindo do estético. In ASSIS SILVA, Ignácio. (org) Corpo e Sentido. São Paulo: UNESP.

1998. "Benedito Ruy Barbosa: Intertextualidade e Recepção. Novos Olhares." Revista de Estudos sobre práticas de recepção a produtos mediáticos. Ano 1, número 1: 10-23, $1^{\circ}$ sem.

. Reflexões sobre intertextualidade em alguns textos fílmicos contemporâneos. in: OLIVEIRA, A.C, \& SANTAELLA, L. (orgs). Semiótica da Comunicação e outras Ciências. São Pau10: EDUC, 1985, 67-72.

2002. O Discurso Ficcional na TV. São Paulo: EDUSP.

BORELLI, Sílvia Helena Simões (org). 1994. Gêneros ficcionais, produção e cotidiano na cultura popular de massa. São Paulo: Coleção GT's-Intercom, n⿳ 1, CNPq, FINEP.

CIEUTAT, Michel. La ville daus le film policier américain. Positif, 172-172, July-Aug, 1975: 26-38.

ECO, Humberto. 1983. Viagem à irrealidade cotidiana. Rio de Janeiro: Nova Fronteira.

EISNER, Lotte. 1985. A Tela Demoníaca. Rio de Janeiro: Paz e Terra.

FAIRCLOUGH, Norman. 1995. Intertextuality and the news. In: Media Discourse. New York: Arnold, 75-101.

FISKE, John. 1987. Television Culture. London, New York: Methuen.

FLOCH, Jean Marie. 1983. Sémiotiques Syncrétiques. Bulletin- Actes Sémiotiques, Paris, VI, 27 sept.

GENETTE, Gérard. 1982. Palimpsestes. La littérature au second degré. Paris: Editions du Seuil.

HITCHCOCK \& TRUFFAUT. 1986. Entrevistas. São Paulo: Brasiliense.

JAKOBSON, Roman. s/d. Lingüística e Comunicação. São Paulo: Cultrix, 64-65. 
JENNY, Laurent. 1976. La stratégie de la forme. In: Poétique. Revue de théorie et d'analyse littéraires, pp. 27; 257-281.

JOHNSON, Randall. 1982 Literatura e Cinema. Macunaíma: do Modernismo na literatura ao Cinema Novo. São Paulo: T.A. Queiroz.

MELLO e ZOUZA, Gilda de. 1979. O tupi e o alaúde. São Paulo: Duas Cidades.

NASCIMENTO, Geraldo Carlos do. 1997. A Intertextualidade em atos de Comunicação. Tese de Doutoramento. São Paulo: ECA/ USP

PFISTER, Manfred. 1994. Concepciones de la Intertextualidad. In Criterios. La Habana: Uneac, Casa de las Américas, no 31, 1-6, 85-108.

PLACE, J.A. \& PETERSON, L.S. 1974. Some Visual Motifs of Film Noir. Film Comment, X/1, Jan-Feb, 30-35.

PLAZA, Júlio. 1991. Las imágenes de tercera generación. Madrid: TELOS, dic. 1990- feb., 93 a 111.

POÉTIQUE. 1976. Revue de théorie et d'analyse littéraires. Paris: du Seuil, nº 27. Intertextualité.

WOLF, Mauro. 1984. Gèneros y televisión. Barcelona: Rev. Análisi, 9: $189-198$. 